LMROS

sabão.

Francisco Antonio Lisboa diz a seu filho que ele deverá completar a escultura do chafariz, no Alto da Cruz. Tarquínio José Barbosa de Oliveira continuando o traçado da História, constata a participação da maçonaria, no movimento da Inconfidência, pela presença do chafariz no Alto da Cruz. Jair Pereira, ao contemplar a igreja de São Francisco, vê, na sacristia, o chafariz esculpido por Aleijadinho. Diante do chafariz do Museu, o povo assiste ao show de Jair Rodrigues pelas honras concedidas à cidade pela Unesco.

$O$ gesto que esculpe a pedra, a escrita que registra a História, o olhar contemplativo e o povo que imprime sua marca nos espaços criam Histórias. Rui Mourão, ao captar todos esses movimentos, mostra que sob a boca do chafariz escondem-se vários modos de olhar e de existir. Com mãos de mestre, recria a História através da ficção. Sua escrita desvela, de modo peculiar, as histórias de Minas, reconstruídas de formas diferentes por outros textos literários como Romanceiro da Inconfidência de Cecilia Meireles e Joaquina, filha do Tiradentes de Maria José de Queiroz.

Se, por um lado, "o tempo comanda os homens e as coisas", em seu livro, Rui Mourão, também motivado pela temporalidade, na luta da vida contra a morte, por seu ato criador, transcende esse e outros tem- pos. No romance Boca de chafariz, o tempo se eterniza.

Haydée Ribeiro Coelho UFMG

\section{ANTROPOFAGIA NA ACADEMIA}

MIRANDA, Wander Melo. Corpos escritos. São Paulo: EDUSP/ED. UFMG, 1992.

Corpos escritos, do mineiro Wander Melo Miranda, é um estudo comparativo das obras de Graciliano Ramos e de Silviano Santiago. Livro destinado aos amantes do tipo de leitura sofisticada que estes dois escritores proporcionam. Ainda mais especialmente, livro destinado aos que amam os meandros da literatura, seus enredos, entrelaces e revezamentos, sua aventura histórica, vivida e compartilhada na linguagem. Antes de virar livro, Corpos escritos foi tese de doutorado defendida e aprovada na USP. Cabe lembrar isso aqui, porque não é pouco mérito. Lembrar a dimensão formal da produção intelectual brasileira, num momento em que as instituições de ensino e pesquisa do país estão sendo extintas ou sucateadas. A USP: bastião supremo de nossa moderna scholarship literária. Sede do importante Instituto de Estudos Brasileiros (cujos arquivos Wander pesquisou, à cata de papéis inéditos de Graciliano). Alma mater do mestre de todos Antonio Candido e da geração operosa composta por seus discípulos diretos.

No entanto, um dos aspectos que mais chama atenção em Corpos escritos é sua posição diferenciada frente à grande tradição uspiana de estudos literários. Uma tradição cuja tendência hegemônica obviamente se alimentou das lições de mestre Candido. Tradição caracterizada por aliar o exercício da crítica à compreensāo e mesmo à construção de teorias e imagens de identidade nacional apoiadas nas ciências sociais e num historicismo totalizador de tipo clássico. Do ponto de vista da história literária, a grande tradição uspiana tratou de construir um cânone modernista no Brasil. No caso de Candido, esse trabalho delineou a contraface acadêmica de um esforço geracional que foi também de Mário de Andrade, Graciliano Ramos, Drummond, Guimarães Rosa. Os discípulos de Candido mantiveram-se presos ao mesmo universo de preocupações, sem embargo da qualidade e das contribuições inegáveis de suas obras críticas individuais.

A linha de trabalho assumida por Wander Melo Miranda indica renovação e complexificação do mapa da crítica universitária brasileira. Existe hoje 
uma novíssima geração de estudiosos com raízes fincadas noutros universos intelectuais, possibilitados historicamente pelos investimentos federais em educação superior nos anos $60 \mathrm{e}$ 70. Tais investimentos permitiram o desenvolvimento de algumas instituições de boa qualidade, capazes de competir, pelo menos na área de Letras, com a grana que as elites paulistas sempre souberam reservar para a USP. Permitiram que, numa terra de bons escritores e de leitores tão meticulosos quanto vorazes como Minas Gerais, surgisse um grupo de pesquisadores literários de bom nível. $O$ traço mais distintivo desse grupo é o interesse pela literatura atual, não apenas através da leitura de obras individuais, mas também da tentativa de definir e analisar os sistemas de sentido que elas expressam e formam.

Em Corpos escritos, Wander realiza uma leitura pioneira do contemporâneo Silviano, acoplada a uma releitura original do clássico modernista Graciliano, reavaliado pela ótica de questões atuais. O Graciliano lido nos anos 90 não pode ser o mesmo lido 40 anos atrás. O Graciliano lido por mim não pode ser igual ao seu. Eis aí dois pressupostos da abordagem operada por Wander. São pressupostos desconstrutivistas. Isto significa dizer que para a nova escola de críticos mineiros, os heróis do panteão modernista não estão nas bibliotecas e livrarias para serem recanonizados.
Eles estão para serem reinterpretados ao avesso das leituras já feitas, já sabidas, já memorizadas. $\mathrm{Na}$ crítica brasileira de agora, desconstruir representa o esforço de abalar os esquemas consagrados de sacralização dos autores modernistas. Não para destruí-los. Claro, nem para derrubá-los do posto que merecidamente ocupam. Mas para forçar a descoberta de dimensões que ficaram na sombra por não terem despertado atenção das gerações anteriores. Outra faceta do desconstrutivismo crítico é nunca pretender chegar a uma conclusão totalizadora sobre o autor ou obra analisada. Trata-se de perseguir aspectos - até mesmo detalhes - considerados estratégicos na elaboração do discurso focalizado.

A leitura acadêmica quer tornarse atividade de corpo a corpo com o texto, como já o é sempre a leitura no aspecto existencial, catártico. Lançando-se ao corpo a corpo com Graciliano, Wander repete o gesto de Silviano no romance-diário $\mathrm{Em}$ liberdade. Só que de outra forma. Em liberdade antropofagiza e incorpora Graciliano como material de composição. Incorpora sua assinatura, pois propōe-se como diário de Graciliano, fictício, embora baseado em dados biográficos reais. Incorpora o texto, pois Silviano copia trechos e parágrafos inteiros de Graciliano, sem dar qualquer indicação de fonte. $E m$ liberdade é um pastiche pós- moderno, e como tal, pioneiro na ficção brasileira.

Como texto crítico que é, Corpos escritos separa Silviano de Graciliano para recombiná-los em perspectiva analítica. Jogo de espelho entre o gesto ficcional de Silviano e o gesto crítico de Wander. Ler Em liberdade obrigou Wander a reler Graciliano e a propor o estudo comparativo mais amplo entre os dois autores. Não para buscar as "influências" do herói modernista sobre o aventureiro pós-moderno. Mas para ajustar as contas com eles. Ou seja, vivenciar (na escrita) a oswaldiana devoração antropofágica pela qual o próprio Silviano teve que passar para afirmar-se definitivamente como ficcionista no Em Liberdade - isto sem minimizar o acerto estético que já tinha sido seu volume de contos de 1970, $O$ Banquete. $\mathrm{O}$ banquete: só mesmo devorando as visceras quentes de meu pai matado posso tê-lo vivo em mim, força que me faz outro. Situada nessa linha, a estratégia comparativa de Wander busca não a derivação que é tradição, mas a deriva que é transformação.

No que diz respeito à análise específica das obras de Silviano, o estudo elaborado por Wander revela então, com rara competência, exatamente de que forma a prática da antropofagia vai definindo a trajetória do autor de $E m$ liberdade, desde o conto juvenil "Pai e Filho", publicado em volume conjunto com Ivan 
Ângelo nos idos de 1961, até a experimentação multiculturalista e anti-homofóbica de Stella Manhattan. Podemos dizer, a partir da leitura de Corpos escritos, que a fase propriamente antropofágica da obra de Silviano abrange o já mencionado e essencial $O$ Banquete, passa pelo livro de poemas-pastiche de 1978 Crescendo durante a guerra e atinge ponto ótimo no Em liberaiade, estendendo tentáculos sobre Stella. Curioso o caráter polimórfico dessa trajetória. Neste particular, Silviano e Graciliano são irmãos espirituais. A obra do velho Graça também conquistou coerência em cima de intensa e deliberada heterogeneidade formal.

É que Graciliano e Silviano compõem figuras intelectuais obcecadas pelo caráter radicalmente intencional, artificial e construído de toda linguagem artística. Por outro lado, para ambos, a escritura é o único lugar onde a experiência existencial pode atestar integridade e autenticidade. $O$ ponto de partida deles é profundamente ético: falar a verdade última do eu. Por isso, são constantemente ameaçados pelo espectro de só conseguirem escrever sobre $o$ vivido, sobre o próximo, sobre o que se inscreve em seus próprios corpos, tatuagem ou fantasma.

No caso de Graciliano, Wander mostra de maneira convincente que a meta ética desemboca na constatação da inexistência de uma verdade última do eu. $\mathrm{O}$ eu só existe como algo permanentemente construído e desconstruído no e pelo discurso: é a constatação da ilusão autobiográfica, para repetir aqui o termo empregado por Wander e que constitui a espinha dorsal de seu argumento teórico. A perda da inocência quanto à ilusão autobiográfica é a virada - estratégica e paradoxal - que faz nascer o escritor ético. Ela é tematizada de diferentes formas em cada uma das obras de Graciliano, com exceção talvez de Vidas secas. Ela é o eixo em torno do qual gira o discurso antropofágico de Silviano.

Perder a inocência. A verdade buscada pelo escritor só pode ser a verdade estética. Só a verdade estética tem existência real como verdade. Através do artifício e da falsificação, só ela é capaz de tocar, mesmo que apenas obliquamente, na vontade de verdade ética que obceca todo intelectual autêntico. $\mathrm{Na}$ escrita modernista de Graciliano, a verdade estética testemunha os embates entre o eu e o social. Ao passo que no pastiche pós-moderno de Silviano, ela testemunha o cruzamento entre o eu e o histórico, encarado nietzscheanamente como eterno retorno. $O$ trabalho de Wander merece menção por ter deslindado em detalhe a trama deste revezamento entre assinaturas.

$\begin{aligned} \text { Italo Moriconi } & \text { E não é ainda sem razão que a } \\ \text { UERJ } & \text { tempestade e a água marcam a } \\ & \text { narrativa em seus momentos } \\ & \text { mais importantes. }\end{aligned}$

PALMEIRA SECA: METÁFORA DE UMA ÉPOCA

SANTOS, Jorge Fermando dos. Palmeira seca. Belo Horizonte: Oficina de Livros, 1992.

A primeira leitura de Palmeira seca, de Jorge Fernando dos Santos, romance ganhador do Prêmio Guimarães Rosa 1989, já desvela o sentido metafórico e metonímico de seu título. Desde o primeiro momento, o leitor pode perceber que a árvore nobre e altiva se relaciona ao Vetho Durval, protagonista atrás do qual se esconde o narrador para contar a estória. Depois do primeiro capítulo onde é descrita a paisagem mineira do interior, marcada pela velha palmeira que sobressai entre os lugares comuns, o narrador, utilizando-se do artigo definido, passa a falar do Velho Durval como se o leitor já o conhecesse: "O velho chama-se Durval e passa a manhã na varanda, sentado numa velha cadeira".

Velha palmeira, velho Durval: duas forças destituídas de vigor. Não é sem razão que o nome Durval, do germânico Thorwald, significa "o que governa sobre Thor, deus dos trovões". E não é ainda sem razão que a narrativa em seus momentos mais importantes. 